\title{
Nederland is het land van de reuzen
}

\section{Inleiding}

Groei is een afspiegeling van de gezondheid van een populatie. Als we naar de Nederlandse geschiedenis kijken, zijn er al sinds het jaar 50 van onze jaartelling gegevens over lengte beschikbaar. Deze gegevens zijn veelal afgeleid uit metingen van pijpbeenderen of skeletten en gebaseerd op kleine aantallen en verschillende bevolkingsgroepen. Opvallend is dat de gemiddelde eindlengte van mannen tussen het jaar 50 en, ongeveer, het jaar 1300 lijkt af te nemen van $176 \mathrm{~cm}$ naar 170 $\mathrm{cm} .{ }^{1}$ Factoren die een rol hebben gespeeld in deze verandering in eindlengte zijn de sociaal-economische condities, die onder andere de beschikbaarheid en kwaliteit van voeding en de hygiëne bepalen. In de periode tussen 1300 en 1825 bleef de eindlengte redelijk stabiel op 170 $\mathrm{cm} .{ }^{1}$ In het jaar 1825 werd voor het eerst een groeistudie gehouden met levende mensen. Deze studie is uitgevoerd onder stadswachten uit zeven steden. De gemiddelde eindlengte was toen $169,0 \mathrm{~cm} .{ }^{1}$ Mensen leefden in die tijd onder slechte sociaal-economische omstandigheden, denk aan werkloosheid, stedelijke overbevolking, voedseltekorten en infectieziekten. Tijdens de industriële revolutie ( 1850 tot 1890$)$ kwamen er steeds meer middelen beschikbaar. Dit zorgde ervoor dat mensen gezonder en langer werden. In de twintigste eeuw nam de welvaart nog verder toe en ook dat is terug te zien in de eindlengte.

\section{Groeistudies}

In totaal vonden er in Nederland vijf grote landelijke groeistudies plaats, namelijk in 1955, 1965, 1980, 1997 en 2009. ${ }^{2-7}$ Remy HiraSing leverde met zijn kennis en netwerk op het gebied van groei, overgewicht en de jeugdgezondheidszorg een belangrijke bijdrage aan de Vijfde Landelijke Groeistudie in 2009 (abstracts 1 en 2). ${ }^{6,7}$ In de eerste vier landelijke groeistudies, die plaatsvonden tussen 1955 en 1997, werd systematisch een toegenomen eindlengte geregistreerd, die globaal evolueerde van 176,0 cm naar 184,0 cm bij mannen en van 163,0 cm naar 170,6 cm bij vrouwen. Ook in andere West-Europese landen vond er een toename in de eindlengte plaats, maar vaak was deze minder sterk.

\section{Lengte en melkconsumptie}

Waarom zijn Nederlanders tussen 1955 en 1997 zoveel langer geworden ten opzichte van de inwoners van de ons omringende landen? Omdat het welvaartspeil vermoedelijk vergelijkbaar evolueerde in deze landen, moeten er andere factoren een rol hebben gespeeld. Het is speculeren. Een mogelijke factor is de zuivelconsumptie. Verschillende studies hebben aangetoond dat er een verband is tussen melkconsumptie en lengtegroei. ${ }^{8}$ Ook is er recent een studie geweest die een relatie vond tussen melkconsumptie tijdens de zwangerschap en de eindlengte van het kind. ${ }^{9}$ Meer onderzoek is nodig om dit resultaat te bevestigen. Nederland staat met $320,15 \mathrm{~kg}$ per capita in de top drie van melkconsumptie wereldwijd, ${ }^{10}$ terwijl de melkconsumptie in de landen om Nederland heen aanzienlijk lager is: België $238,47 \mathrm{~kg}$, Duitsland 247,24 kg en Engeland 241,47 kg. Als we de gemiddelde (gemeten) eindlengte uitzetten tegen de corresponderende melkconsumptie per capita in verschillende landen, zien we een sterke relatie (figuur 1A). ${ }^{10,11}$ Analoog hieraan is er ook een relatie tussen het bruto nationaal product (BNP) per capita en de gemiddelde (gemeten) eindlengte (figuur 1B)..$^{12}$ Maar zelfs na correctie voor het BNP blijft de relatie tussen melkconsumptie per capita en eindlengte significant. Mogelijk hebben we de snelle toename in eindlengte in Nederland dus voor een deel te danken aan melk.

\section{Lengte en overgewicht}

Een andere factor die het verschil in lengtegroei zou kunnen verklaren, is de relatief lage prevalentie van overgewicht onder Nederlandse kinderen. Sommige groeibevorderende hormonen worden mogelijk versterkt door de aanwezigheid van obesitas, wat de groeispurt en het optreden van de puberteit kan vervroegen. ${ }^{13}$ Een vroegere rijping of een vroegere groeispurt zou kunnen leiden tot het eerder stoppen van de lengtegroei. ${ }^{13}$ Hierover is echter nog geen consensus. ${ }^{13}$ Zonder een uitspraak te doen over de causaliteit, noemen we hier de toename van overgewicht in Nederland onder 2- tot 21-jarigen (van 1 op de 17 kinderen in 1980 naar 1 op de 7 kinderen in 2009), en het feit dat de gemiddelde leeftijd waarop meisjes ongesteld worden steeds verder naar voren schuift. De gemiddelde menarcheleeftijd is tussen 1980 en 2009 namelijk afgenomen van 13,28 naar 13,05 jaar, een verschil van bijna drie maanden. ${ }^{14}$ Verder zien we dat Nederland een lagere prevalentie van overgewicht heeft ten opzichte van de omringende landen. Rond 1997 had in Nederland $11 \%$ van de 7- tot 11-jarigen overgewicht, ${ }^{6}$ in België was dit ongeveer $13 \%,{ }^{15}$ in Duitsland 16\% en in Engeland $20 \% .{ }^{16}$ Ongeveer tien jaar later had $14 \%$ van de Nederlandse 4 - tot 16 -jarigen overgewicht, tegenover $20 \%$ van de Duitse 4 - tot 16 -jarigen en $25 \%$ van Britse 5 - tot 17 -jarige kinderen. ${ }^{17}$ Mogelijk zijn kinderen in Nederland dus harder gegroeid ten opzichte

P. van Dommelen, statisticus, onderzoeker, TNO, Leiden. S. van Buuren, statisticus, onderzoeker, TNO, Leiden en Universiteit Utrecht, Utrecht.

M. Roelants, statisticus, onderzoeker, Dienst Jeugdgezondheidszorg, KU Leuven, Leuven, België. Correspondentie: paula.vandommelen@tno.nl. 


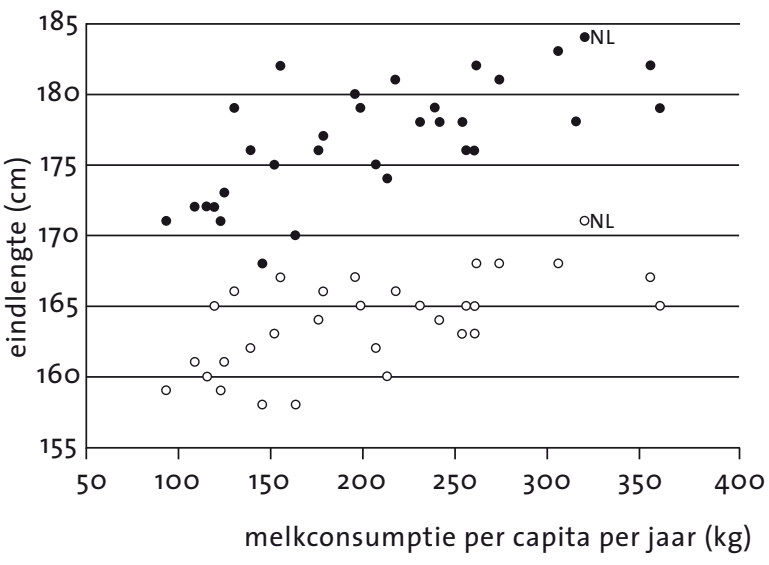

A - mannen ovrouwen

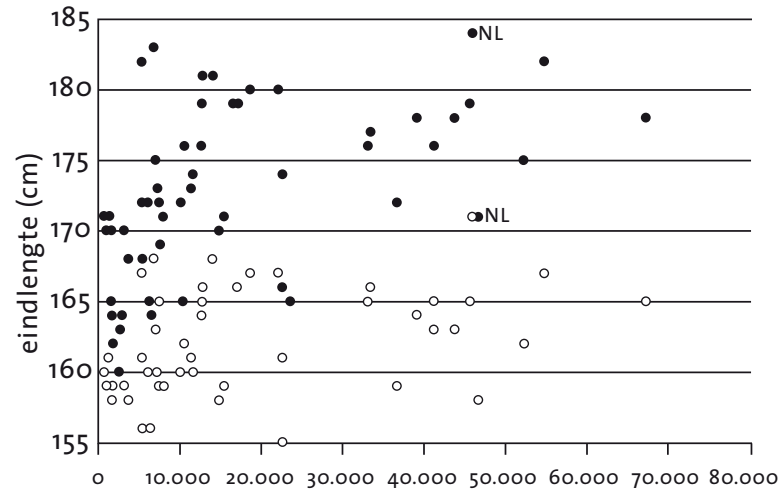

bruto binnenlands product per capita (VS dollars)

B

Figuur 1. De gemiddelde (gemeten) eindlengte per capita in verschillende landen (waarvan gegevens beschikbaar zijn) uitgezet tegen (A) melkconsumptie ('uitbijter' India is verwijderd) en (B) bruto binnenlands product ('uitbijter' Noorwegen is verwijderd)

van de kinderen in de omringende landen, omdat de prevalentie van overgewicht in Nederland lager is.

\section{Gelukkige reuzen}

En nu? Uit de resultaten van de Vijfde Landelijke Groeistudie uit 2009, de groeistudie waaraan Remy HiraSing een belangrijke bijdrage leverde, blijkt dat de Nederlandse kinderen inmiddels zijn uitgegroeid. ${ }^{7}$ Ondanks deze trendbreuk is Nederland van alle landen van de wereld nog steeds het land met de hoogst gemiddelde eindlengte. De gemiddelde eindlengte staat op 183,8 cm bij mannen en 170,7 cm bij vrouwen.7 Kortom, Nederland is een land vol reuzen. Gelukkige reuzen, want uit onderzoek blijkt dat lange mensen gemiddeld genomen gelukkiger zijn en ook meer plezier ervaren dan minder lange mensen. ${ }^{18}$ We moeten hier nog wel bij vermelden dat alle bovenstaande eindlengtes niet zijn gecorrigeerd voor het zeeniveau. Anders blijven er slechts dwergen over.

\section{Literatuur}

1. Maat GJR. Hoe lang nog? De lichaamslengte van de Nederlander. Mei 2006. Beschikbaar via: http://media.leidenuniv.nl/ legacy/2006\%20Hoe\%2olang\%2onog.pdf. Geraadpleegd 1 november 2013

2. Wijn JF de, Haas JH de. Growth diagrams for ages 1-25 years in the Netherlands. Leiden: Nederlands Instituut voor Praeventieve Geneeskunde; 1960.

3. Wieringen JC van, Wafelbakker F, Verbrugge HP, Haas JH de. Growth diagrams 1965 in the Netherlands. Leiden/Groningen: Nederlands Instituut voor Praeventieve Geneeskunde/ Wolters-Noordhoff; 1965

4. Roede MJ, Wieringen JC van. Growth diagrams 1980: Netherlands third nationwide survey. Tijdschr Soc Gezondheidsz. 1985;63:1-34.

5. Fredriks AM, Buuren S van, Burgmeijer RJ, Meulmeester JF, Beuker RJ, Brugman E, e.a. Continuing positive secular growth change in the Netherlands 1955-1997. Pediatr Res. 2000;47:316-23.
6. Schönbeck Y, Talma H, Dommelen P van, Bakker B, Buitendijk $\mathrm{SE}$, Hirasing RA, Buuren S van. Increase in prevalence of overweight in Dutch children and adolescents: a comparison of nationwide growth studies in 1980, 1997 and 2009. PLoS One. 2011;6(11):e27608.

7. Schönbeck Y, Talma H, Dommelen P van, Bakker B, Buitendijk SE, HiraSing RA, Buuren S van. The world's tallest nation has stopped growing taller: the height of Dutch children from 1955 to 2009. Pediatr Res. 2013;73:371-7.

8. Wiley AS. Does milk make children grow? Relationships between milk consumption and height in NHANES 19992002. Am J Hum Biol. 2005;17:425-41.

9. Hrolfsdottir L, Rytter D, Hammer Bech B, Brink Henriksen T, Danielsen I, Steingrimsdottir L, e.a. Maternal milk consumption, birth size and adult height of offspring: a prospective cohort study with 20 years of follow-up. Eur J Clin Nutr. 2013;67:1036-41.

10. FAO Statistics Division: Total milk consumption (excluding butter) per capita, year 2007. http://faostat.fao.org/site/610/ DesktopDefault.aspx (23 september 2013).

11. Diverse bronnen, beschikbaar op http://en.wikipedia.org/ wiki/Human_height (23 september 2013).

12. International Monetary Fund. World Economic Outlook Database-October 2013. http://www.imf.org/external/pubs/ft/ weo/2013/o2/weodata/index.aspx (1 november 2013).

13. He Q, Karlberg J. BMI in childhood and its association with height gain, timing of puberty, and final height. Pediatr Res. 2001 Feb;49(2):244-51.

14. Talma H, Schönbeck Y, Dommelen P van, Bakker B, Buuren S van, Hirasing RA. Trends in menarcheal age between 1955 and 2009 in the Netherlands. PLoS One. 2013;8(4):e60056.

15. Roelants M, Hoppenbrouwers K. Prevalentie van obesitas bij kinderen en jongeren op basis van de body mass index. Tijdschrift JGZ. 2002;34:88-92.

16. Lobstein T, Frelut ML. Prevalence of overweight among children in Europe. Obes Rev. 2003;4:195-200. 
17. Global childhood overweight September 2011. International Association for the Study of Obesity. http://www.iaso.org/ site_media/uploads/Global_Childhood_Overweight_September_2011.pdf (1 november 2013).

18. Deaton A, Arora R. Life at the top: the benefits of height. Econ Hum Biol. 2009;7:133-6.

\section{Bijlage}

Abstract 1. Toename in de prevalentie van overgewicht bij Nederlandse kinderen en adolescenten: een vergelijking van nationale groeistudies uit 1980, 1997 en 2009

Schönbeck Y, Talma H, Dommelen P van, Bakker B, Buitendijk SE, Hirasing RA, Buuren S van. PLoS One. $2011 ; 6(11)$ :e27608. Epub 2011 Nov 15.

\section{Doel}

Bepalen van de prevalentie van overgewicht en obesitas bij Nederlandse kinderen en adolescenten; onderzoeken van de trend van de afgelopen 30 jaar; maken van nieuwe body mass index (BMI) Groeidiagrammen.

\section{Design}

Nationale cross-sectionele dataverzameling door getrainde gezondheidszorgprofessionals. Deelnemers: 10.129 kinderen van o tot 21 jaar van Nederlandse afkomst. Primaire uitkomstmaten waren prevalenties van overgewicht (inclusief obesitas) en obesitas bij Nederlandse kinderen, vastgesteld met de afkapwaarden voor BMI van de Internationale Obesity Task Force.

\section{Resultaten}

In 2009 hadden $12,8 \%$ van de Nederlandse jongens en $14,8 \%$ van de Nederlandse meisjes van 2 tot 21 jaar overgewicht; $1,8 \%$ van de jongens en $2,2 \%$ van de meisjes waren obees. Dit betekent een twee- tot driemaal zo hoge prevalentie van overgewicht en een vier- tot zesmaal hogere prevalentie van obesitas sinds 1980 . Sinds 1997 is er een substantiële toename, met name voor de prevalentie van obesitas: deze nam bij meisjes toe met een factor 1,4 en verdubbelde bij jongens. Sinds 1997 is de gemiddelde BMI-standaarddeviatiescore (SDS) in de grote steden niet toegenomen.

\section{Conclusies}

De prevalenties van overgewicht en obesitas waren in 2009 substantieel hoger dan in 1980 en 1997. Echter, de prevalentie van overgewicht stabiliseerde in de grote steden. Dit kan erop wijzen dat de stijgende trend van overgewicht in deze grote steden begint te stagneren.
Abstract 2. 's Werelds langste natie is gestopt met groeien: de lengte van Nederlandse kinderen tussen 1955 en 2009

Schönbeck Y, Talma H, Dommelen P van, Bakker B, Buitendijk SE, Hirasing RA, Buuren S van. Pediatr Res.2013 Mar;73(3):371-7. Epub 2012 Dec 10.

\section{Achtergrond}

Historische data laten zien dat sinds het jaar 1858 de gemiddelde lengte in Nederland is toegenomen. Dit onderzoek analyseert of deze trend in de langste natie ter wereld zich voortzet en wat de invloed is van de geografische regio en de opleiding van het kind en de ouders op de veranderingen in lengte.

\section{Methode}

Wij vergeleken de lengte van Nederlanders in de leeftijd van o tot 21 jaar uit de groeistudie van 2009 met gegevens over de lengte van deze groep in de groeistudies uit 1955, 1965, 1980 en 1997.

\section{Resultaten}

De steekproef bestond uit 5811 jongens en 6194 meisjes. In 2009 kwam de verdeling van lengte naar leeftijd overeen met die in 1997. De gemiddelde eindlengte was $183,8 \mathrm{~cm}(\mathrm{sd}=7,1 \mathrm{~cm})$ bij jongens en $170,7 \mathrm{~cm}(\mathrm{sd}=6,3)$ bij meisjes. Het opleidingsniveau van zowel kinderen als ouders hangt positief samen met de gemiddelde lengte. Sinds 1997 zijn de verschillen tussen regio's afgenomen, maar niet verdwenen. De populatie in het Noorden is nog steeds het langst.

\section{Conclusie}

's Werelds langste populatie is na een periode van 150 jaar gestopt met groeien. De oorzaak hiervan is onbekend. Mogelijk hebben de Nederlanders de optimale lengteverdeling bereikt. Het kan ook zijn dat omgevingsfactoren die de groei bevorderen zich in het afgelopen decennium hebben gestabiliseerd, waardoor wordt voorkomen dat de populatie haar volle groeipotentieel bereikt. 